\title{
Social and sexual risk factors for bacterial vaginosis
}

\author{
S Smart, A Singal, A Mindel
}

Sex Transm Infect 2004;80:58-62. doi: 10.1136/sti.2003.004978

Background: A number of sexual and social risk factors for bacterial vaginosis (BV) have been identified. However, many previous studies have used small numbers of patients, or highly selected or convenience samples, or poorly defined populations. This study aims to clarify potential sexual and non-sexual risk factors for BV.

See end of article for authors' affiliations Methods: Women attending the Sydney Sexual Health Centre with BV, between March 1991 and July 1999, were included. Controls were randomly selected women without BV. Information on the demographics, clinical findings, and sexual and non-sexual risk behaviours were extracted from the

Correspondence to: A Mindel, Sexually Transmitted Infections Research Centre, The University of Sydney, Marian Villa, Westmead Hospital, Westmead, NSW 2145 , Australia; adrianm@icpmr. wsahs.nsw.gov.au clinic database and analysed using SPSS and SAS. A logistic regression model was used to establish which associations with BV persisted.

Results: 890 women with BV and 890 controls were studied. Factors that were independently associated with $B V$ were $\geqslant 3$ male sexual partners in the past 12 months $(O R=1.60,95 \% \mathrm{Cl}: 1.19$ to 2.04$)$, at least one female sexual partner in the past 12 months $(O R=2.1, p=0.003)$, a past pregnancy $(O R=1.5$, $\mathrm{p}<0.0006$ ), and smoking. In contrast, women with BV were significantly less likely to have used hormonal contraception $(\mathrm{OR}=0.60,95 \% \mathrm{Cl}$ : 0.51 to 0.81$)$ or to have used condoms consistently $(\mathrm{OR}=0.5,95 \% \mathrm{Cl}$ : 0.31 to 0.71 ) than controls.

Accepted for publication 29 April 2003

Conclusion: Our findings may be important for planning a preventive strategy for BV by discouraging smoking and increasing condom use and hormonal contraception among women.

B acterial vaginosis $(\mathrm{BV})$ is a common clinical entity characterised by abnormal greyish white, homogenous, malodorous vaginal discharge. It results from an overgrowth of anaerobic bacteria in the vagina replacing or markedly reducing the normal vaginal flora. ${ }^{1}$ Up to $50 \%$ of women harbouring these abnormal bacteria are asymptomatic. ${ }^{2}$

The prevalence of BV varies from $5-26 \%$ in pregnant women $^{3-8}$ to $24-37 \%^{2}{ }^{9-11}$ in those attending sexually transmitted infection (STI) clinics. BV is associated with pelvic inflammatory disease (PID), significant reproductive morbidity, including premature rupture of membranes and preterm delivery, and increased risk of HIV transmission and acquisition. Hence, timely therapeutic intervention and preventive strategies in selected populations may decrease BV associated morbidity and the risk of HIV transmission. Treatment with metronidazole has a reported cure rate of $78-85 \%$ compared with clindamycin $(82-85 \%)$, but recurrences are common. ${ }^{12}{ }^{13}$ Hence, it may be important to explore primary preventive strategies.

Preventive strategies target the risk factors or behaviours for a disease. Previous studies have identified a number of risk factors and behaviours associated with BV, including the number of lifetime male sexual partners, recent partner change, lower age of first intercourse, having had a female sexual partner in the past 12 months, being unemployed, being unmarried, working as a sex worker, smoking, and failure to use condoms. ${ }^{13-18}$ However, many previous studies have used small numbers of patients, or highly selected or convenience samples, or poorly defined patient populations. There is a paucity of published literature investigating risk variables for BV, particularly in Australian populations. Consequently, this study aims at investigating the potential sexual and non-sexual risk factors for BV in an urban sexual health clinic population in Australia.

\section{METHODS}

\section{Study subjects}

Subjects included all women diagnosed with BV on their first clinic visit to the Sydney Sexual Health Centre (SSHC) between March 1991 and July 1999. Controls were randomly selected from those who first attended the clinic on the same day as the study subjects but without a diagnosis of BV. Ethical approval was obtained from South Eastern Sydney Area Health Service research ethics committee. All data were de-identified and only group data were analysed. Consequently, individual consent was not obtained.

\section{Data collection}

Detailed information on the demographics, clinical findings, and sexual and non-sexual health risk behaviours were extracted from the SSHC computerised database. This information was originally recorded on standardised medical records and entered into the database after verification by trained staff. Missing information was retrieved from the clinical case notes. To avoid selection bias, no patient was excluded from the study irrespective of the completeness of data. A wide range of demographic, clinical, sexual and nonsexual risk behaviour data were evaluated. These included age; marital status (never married, married/de facto, separated/divorced/widowed); occupation; ethnic origin; country of birth; contraception; parity; number of male and female sexual partners in the past 3 months, 12 months and lifetime; condom use; cigarette smoking; alcohol intake; injecting drug use (IDU); and concurrent STI diagnoses. Age was grouped into a categorical variable ( $\leqslant 19,20-29,30-39, \geqslant 40$ years) for analysis. Condom use was classified as none, sometimes $(<50 \%$ of times), usually ( $>50 \%$ of times), and always $(100 \%$ of times). Cigarette smoking was classified as 0, 1-9, 10-19, $\geqslant 20$ cigarettes per day and alcohol intake as $\geqslant 140 \mathrm{~g}$ per week or $\leqslant 140 \mathrm{~g}$ per week. STIs included gonorrhoea, chlamydia, genital herpes, genital human papillomavirus, PID, trichomonas, syphilis, and candidiasis. The diagnosis of BV was based on Spiegel's Gram stain criteria and on the presence of clue cells on microscopic examination of the vaginal smear.

\section{Statistical methods}

Data cleaning, manipulation, and statistical analysis were undertaken using SPSS and SAS. Comparisons between 
patients and controls were assessed using Pearson $\chi^{2}$ test. Univariate analysis was used to calculate crude odds ratio (OR) and 95\% confidence interval (CI). A backwards elimination logistic regression model for multivariate analysis was used to establish which association with BV persisted. The variables included in multivariate analysis were those significant on univariate analysis at $\mathrm{p}<0.05$ and those considered important based on published literature. The variables significant at $\mathrm{p}<0.01$ in the final logistic regression model were analysed individually to obtain unadjusted OR and as a group to obtain adjusted OR. A test for trend was performed on factors found significant on multivariate analysis.

\section{RESULTS}

Of the 15567 first clinic women who attended SSHC during the study period, 890 (5.7\%) were diagnosed with BV. Table 1 compares the demographic characteristics, obstetric history, and use of contraception of women with BV and controls. The demographic variables comparing women with BV and controls were similar. However, women with BV were statistically significantly more likely to be separated, divorced, or widowed $(\mathrm{p}=0.01)$, more likely to be unemployed $(p=0.04)$, and more likely to be have been born in Asia $(p=0.05)$ than controls although the differences between the groups were small.

Women with BV were significantly less likely to be using hormonal contraception $(\mathrm{p}<0.0001)$, more likely to use IUD $(p=0.003)$ or nil/inadequate contraception $(p=0.02)$ than those who did not have the condition. Patients with BV were more likely to have a past pregnancy than controls $(\mathrm{p}<0.001)$.

\section{Concurrent STIs and sexual risk behaviour (table 2)}

Women with BV had a significantly higher rate of concurrent PID (OR $=2.50,95 \%$ CI: 1.38 to $1.64, p=0.002)$ and a lower rate for genital herpes $(\mathrm{OR}=0.50,95 \% \mathrm{CI}$ : 0.34 to 0.72 , $\mathrm{p}=0.002)$ and candidiasis (OR $=0.70,95 \%$ CI: 0.50 to 0.97 , $\mathrm{p}=0.03)$ than controls.

Women with two or more male partners in the past 3 months (OR $=1.50,95 \%$ CI: 1.18 to 1.85 ) and three or more in the past 12 months (OR $=1.60,95 \%$ CI: 1.27 to 2.02 ) were significantly more likely to have BV than those with fewer partners. Women with one or more female partners in the last 12 months ( $\mathrm{OR}=2.30,95 \% \mathrm{CI}: 1.48$ to 3.54$)$ and two or more in their lifetime (OR $=2.00,95 \% \mathrm{CI}$ : 1.32 to 2.95$)$ were more likely to have BV than those with fewer or no female sexual partners. Women with BV were significantly less likely to always use condoms in comparison to women without BV $(\mathrm{OR}=0.70,95 \% \mathrm{CI}: 0.51$ to 0.85$)$.

\section{Social risk behaviour (table 3)}

Women with BV were significantly more likely to consume higher quantities of alcohol $\geqslant 140$ g per week ( $13 \% \vee 10 \%$, $\mathrm{OR}=1.4, \mathrm{p}=0.04$ ), to report injecting drug use in the past $(8 \% \vee 4 \%, \mathrm{OR}=0.4, \mathrm{p}<0.0001)$, and to be smokers than those without $\mathrm{BV}(51 \% v 36 \%$, OR $=1.8, \mathrm{p}<0.0001)$. In addition, the number of cigarettes smoked per day by women with BV was significantly higher than controls.

\section{Multivariate analysis (table 4)}

Age, occupation, marital status, hormonal contraception, IUD, nil/inadequate contraception, past pregnancy, male sexual partners (past 12 months), $\geqslant 1$ female sexual partners (past 12 months), condom use, cigarettes per day, alcohol intake, and IDU were included in multivariate analysis. Genital HSV, PID, termination of pregnancy, miscarriage, and live births, though found significant on univariate analysis, were not included independently in the logistic regression as they were not considered causal/risk variables for BV.

Table 1 Demographic characteristics, contraceptive use, and obstetric history of women with BV compared with controls (univariate analysis)

\begin{tabular}{|c|c|c|c|c|}
\hline Characteristic & $\begin{array}{l}\text { Women with BV } \\
n=890(\%)\end{array}$ & $\begin{array}{l}\text { Controls } \\
n=890(\%)\end{array}$ & Odds ratio $(95 \% \mathrm{Cl})$ & $\begin{array}{l}\text { p Value } \\
\text { (overall) }\end{array}$ \\
\hline Age (y) & & & & (NS) \\
\hline$\leqslant 19$ & $51 / 889(6)$ & $67 / 890(8)$ & $0.80(0.52$ to 1.11$)$ & NS \\
\hline $20-29$ & $530 / 889(60)$ & $527 / 890(59)$ & 1 & - \\
\hline $30-39$ & $223 / 889(25)$ & $213 / 890(24)$ & 1.00 (0.83 to 1.30$)$ & NS \\
\hline$\geqslant 40$ & $85 / 889(9)$ & $83 / 890(9)$ & $1.00(0.74$ to 1.41$)$ & NS \\
\hline Marital status & & & & $(0.005)$ \\
\hline Never married & $592 / 867(68)$ & $601 / 864$ (69.5) & 1 & - \\
\hline Married/de facto & $139 / 867(16)$ & $169 / 864(19.5)$ & 0.80 (0.65 to 1.07$)$ & NS \\
\hline Separated/divorced/widowed & $136 / 867(16)$ & $94 / 864(11)$ & 1.50 (1.10 to 1.96$)$ & 0.01 \\
\hline Occupation & & & & $(<0.05)$ \\
\hline Employed & $450 / 852(53)$ & $492 / 859$ (57) & 1 & - \\
\hline Unemployed & $151 / 852(18)$ & $124 / 859(14)$ & 1.30 (1.02 to 1.74$)$ & $<0.05$ \\
\hline Benefits & $34 / 852(4)$ & $23 / 859$ (3) & 1.60 (0.94 to 2.79$)$ & NS \\
\hline Home duty & $45 / 852(5)$ & $34 / 859$ (4) & 1.50 (0.91 to 2.30$)$ & NS \\
\hline Student & $112 / 852(13)$ & $138 / 859(16)$ & $0.90(0.67$ to 1.74$)$ & NS \\
\hline Sex work & $60 / 852(7)$ & $48 / 859(6)$ & $1.40(0.92$ to 2.04$)$ & NS \\
\hline Country of birth & & & & (NS) \\
\hline Australia/NZ & $452 / 832(54)$ & $504 / 833(61)$ & 1 & - \\
\hline N America/Europe & $198 / 832(24)$ & $169 / 833(20)$ & $1.10(0.43$ to 2.74$)$ & NS \\
\hline Asia & $132 / 832(16)$ & $123 / 833(15)$ & 1.30 (1.00 to 1.60$)$ & 0.05 \\
\hline Others & $51 / 832(6)$ & $36 / 833(4)$ & 1.20 (0.88 to 1.52$)$ & NS \\
\hline \multicolumn{5}{|l|}{ Contraceptive used } \\
\hline Hormonal & $238 / 835$ (29) & $307 / 822$ (37) & $0.70(0.54$ to 0.82$)$ & $<0.0001$ \\
\hline IUD & $45 / 835(5)$ & $20 / 822(2)$ & 2.30 (1.34 to 3.90$)$ & $<0.01$ \\
\hline Diaphragm/cervical cap & $24 / 835(3)$ & $24 / 822(3)$ & 1 & - \\
\hline $\mathrm{Nil} /$ inadequate & $256 / 835(31)$ & $211 / 822(26)$ & 1.30 (1.03 to 1.59$)$ & $<0.05$ \\
\hline \multicolumn{5}{|l|}{ Obstetric history } \\
\hline Past pregnancy & $489 / 865$ (57) & $391 / 862(45)$ & $1.60(1.30$ to 1.89$)$ & $<0.0001$ \\
\hline Termination of pregnancy & $291 / 726(40)$ & $226 / 729(31)$ & 1.50 (1.20 to 1.78$)$ & $<0.001$ \\
\hline Miscarriage & $128 / 723(18)$ & $88 / 725(12)$ & 1.60 (1.18 to 2.06$)$ & $<0.01$ \\
\hline Live birth & $184 / 723(25)$ & $129 / 724(18)$ & 1.50 (1.19 to 1.88$)$ & $<0.001$ \\
\hline
\end{tabular}




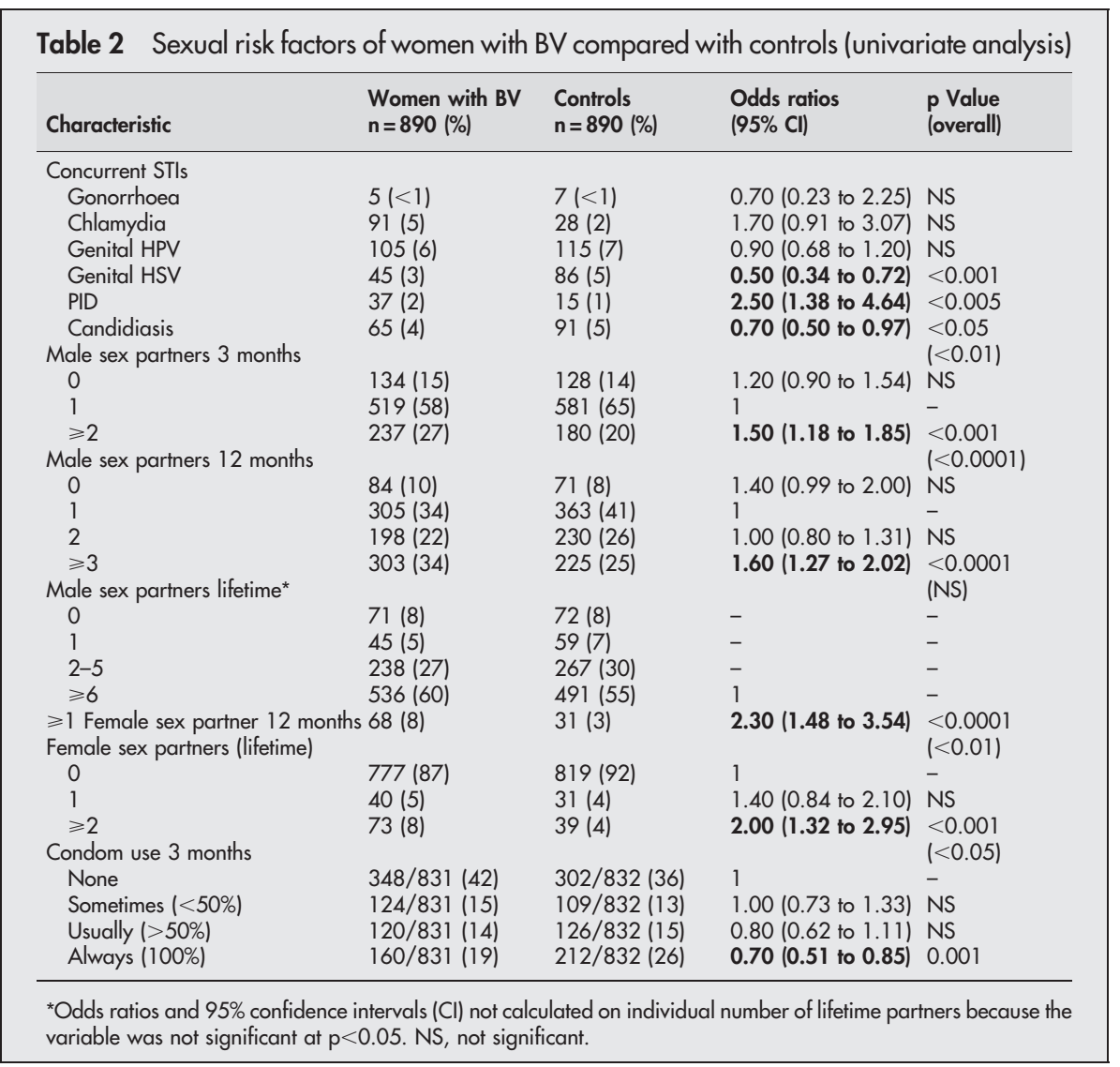

Factors that were independently associated with BV were $\geqslant 3$ male sexual partners in the past 12 months $(\mathrm{OR}=1.6$, $\mathrm{p}=0.001)$, at least one female sexual partner in the past 12 months $(\mathrm{OR}=2.1, \mathrm{p}=0.003)$, a past pregnancy $(\mathrm{OR}=1.5$, $\mathrm{p}<0.0006$ ), and smoking. A test for trend for cigarette smoking was significant, indicating that the risk of $\mathrm{BV}$ increased as the number of cigarettes smoked daily increased (trend $\chi^{2}=20.031 \mathrm{df}, \mathrm{p}<0.0001$ ). In contrast, women with $\mathrm{BV}$ were significantly less likely to have used hormonal contraception (OR $=0.6,95 \% \mathrm{CI}$ : 0.51 to 0.81 ) or to have used condoms consistently ( $\mathrm{OR}=0.5,95 \% \mathrm{CI}: 0.31$ to 0.71 ) than controls.

\section{DISCUSSION}

This study showed that several sexual, reproductive, and social risk variables were independently associated with BV. Women with a past pregnancy, more than three male sexual partners in past 12 months, one or more female sexual partner in past 12 months, and cigarette smoking were all more likely to have BV, whereas those on hormonal contra- ception and those using condoms usually or always were less likely to have BV. Cigarette smoking was the strongest independent non-sexual risk factor for $\mathrm{BV}(\mathrm{OR}=1.9,95 \%$ CI: 1.40 to 2.61$)$ and the risk of BV was directly proportional to the number of cigarettes smoked. Smoking has been found to be associated with $\mathrm{BV}$ in previous studies. ${ }^{14}{ }^{19-21}$ Possible pathogenic mechanisms linking cigarette smoking and BV need further exploration. One possible explanation is that cigarette smoke contains various chemical constituents like nicotine, cotinine, and benzo[a]pyrene diol epoxide (BPDE). These chemicals have been demonstrated in cervical mucus of smokers and may directly alter the vaginal microflora or may act by depleting Langerhans cells in cervical epithelium leading to local immunosuppression. ${ }^{23}$ This may be responsible for change of cervical flora causing BV.

BV was independently associated with a number of sexual factors, including multiple male sexual partners in last 12 months and one or more female sexual partner in past 12 months. Other studies have also reported an association

Table 3 Non-sexual risk behaviour of women with BV compared with controls (univariate analysis)

\begin{tabular}{lllll}
\hline Characteristic & $\begin{array}{l}\text { Women with BV } \\
\mathbf{n}=890(\%)\end{array}$ & $\begin{array}{l}\text { Controls } \\
\mathbf{n}=890(\%)\end{array}$ & $\begin{array}{l}\text { Odds ratio } \\
(95 \% \mathrm{CI})\end{array}$ & $\mathrm{p}$ Value (overall) \\
\hline $\begin{array}{l}\text { Alcohol intake }(\geqslant 140 \mathrm{~g} / \text { week) } \\
\text { Smoker }\end{array}$ & $113(13)$ & $85(10)$ & $1.40(1.02$ to 1.85$)$ & $<0.05$ \\
Cigarettes per day & $453(51)$ & $323(36)$ & $1.80(1.50$ to 2.20$)$ & $<0.0001$ \\
0 & $437(49)$ & $566(64)$ & 1 & $(<0.0001)$ \\
$1-9$ & $134(15)$ & $112(12)$ & $1.60(1.71$ to 2.05$)$ & $<0.01$ \\
$10-19$ & $148(17)$ & $116(13)$ & $1.70(1.26$ to 2.17$)$ & $<0.001$ \\
$\geqslant 20$ & $171(19)$ & $95(11)$ & $2.30(1.76$ to 3.09$)$ & $<0.0001$ \\
Injecting drug use & $69 / 885(8)$ & $34 / 873(4)$ & $1.40(1.02$ to 1.85$)$ & $<0.0001$ \\
\hline
\end{tabular}


Table 4 Risk variables independently associated with BV

\begin{tabular}{|c|c|c|}
\hline \multirow{4}{*}{$\begin{array}{l}\text { Characteristic } \\
\text { Hormonal contraception } \\
\text { Past pregnancy }\end{array}$} & \multicolumn{2}{|c|}{ Adjusted OR $(95 \% \mathrm{Cl})^{*} \mathrm{p}$ Value } \\
\hline & $0.60(0.51$ to 0.81$)$ & $<0.0001$ \\
\hline & $1.50(1.18$ to 1.80$)$ & $<0.001$ \\
\hline & \multicolumn{2}{|c|}{ Male partners (past 12 months) } \\
\hline 0 & 1.20 (0.78 to 1.90$)$ & NS \\
\hline 1 & 1 & - \\
\hline 2 & 1.00 (0.78 to 1.35$)$ & NS \\
\hline$\geqslant 3$ & 1.60 (1.19 to 2.04$)$ & 0.001 \\
\hline$\geqslant 1$ female partner (past & 2.00 (1.27 to 3.33 ) & $<0.01$ \\
\hline 12 months) & & \\
\hline \multicolumn{3}{|c|}{ Condom use (past 3 months) } \\
\hline None & 1 & - \\
\hline Sometimes & 0.80 (0.59 to 1.14$)$ & NS \\
\hline Usually & 0.60 (0.43 to 0.83 ) & $<0.01$ \\
\hline Always & $0.50(0.3$ to 0.71$)$ & $<0.001$ \\
\hline \multicolumn{3}{|l|}{ Cigareftes per day } \\
\hline 0 & 1 & - \\
\hline $1-9$ & 1.40 (1.03 to 1.89$)$ & $<0.05$ \\
\hline $10-19$ & 1.50 (1.09 to 2.01 ) & $<0.05$ \\
\hline$\geqslant 20$ & 1.90 (1.40 to 2.61 ) & $<0.0001$ \\
\hline
\end{tabular}

between BV and sexual factors, including the lifetime number of sexual partners, recent partner change, and lower age of first intercourse. ${ }^{14-18,23}$ One possible explanation is that there is an exogenous "factor" in semen that may create an imbalance in vaginal microflora necessary for the development of BV or transmission of an as yet unknown STI. Exposure to this may occur more frequently in women who have more partners and in those who use condoms inconsistently. The observation that women who used condoms consistently were less likely to have bacterial vaginosis suggests that condoms may be useful both in preventing $\mathrm{BV}$ and also in reducing the likelihood of recurrences in women prone to the infection. A randomised controlled study to evaluate the latter suggestion should be considered.

Several studies have reported on the increased incidence of $\mathrm{BV}$ in women who have sex with women (WSW)..$^{24-27}$ The pathogenesis of BV in WSW is not clear. McCaffrey et al were not able to link any specific sexual practice to $\mathrm{BV}$ in lesbians, ${ }^{25}$ although receptive cunnilingus has been recently linked to BV in WSW. ${ }^{28}$ One possible explanation is that there are many similarities between the anaerobic bacteria associated with gingivitis and those associated with BV. Detailed studies are required in this group of WSW to delineate their propensity to develop BV.

We found that gravidity was independently associated with BV. In addition, on univariate analysis, we found that termination of pregnancy, miscarriage, and live birth were each associated with increased risk of BV. We are unaware of any previous published data showing similar findings, though women who are diagnosed with BV during pregnancy are more likely to have a termination than those who are not. ${ }^{29}$ The reasons for this finding are unclear but may be related to changes in the vaginal flora as a consequence of hormonal factors or perhaps changes in sexual behaviour during pregnancy. Little is known about sexual behaviour during pregnancy although a recent study suggested that cunnilingus was common. ${ }^{30}$ In addition, there is some evidence to suggest that male partners commonly have unprotected vaginal sex with other women during their partner's pregnancy. ${ }^{31}$

Women using hormonal contraceptives were found to be at a lower risk for BV, as has been reported in many previous studies, ${ }^{15} 32$ but interestingly have a high risk of acquiring chlamydia and vaginal candidiasis. ${ }^{31}$ Oestrogens stimulate vaginal epithelial cells to produce more glycogen. This creates a more favourable environment for lactobacilli and thus may prevent colonisation by anaerobes, although a clear mechanism still remains undefined. Previous studies have demonstrated positive relation between IUD and BV but in our study IUD, though significant on univariate analysis, was not independently associated with development of BV. ${ }^{32}$

The strengths of this study include the large sample size, the diversity of the sexual reproductive and social risk variable history we were able to obtain, the study design, and the statistical analysis we were able to perform. Consequently, we believe that this study has helped to clarify the diverse and often conflicting risk variable information about BV.

Potential limitations of the study include the use of data that were derived from an existing database with the possibility of less rigorous standards of diagnosis for BV and other conditions than would be possible in a prospective study. Additionally, it was not possible to obtain information on certain factors of potential relevance, such as cunnilingus. Secondly, in common with some previous studies, this was a "convenience" sample. Finally, although a number of factors were found to be associated with BV, the small odds ratios suggest that the individual predictive values maybe low.

In conclusion, we found both sexual and non-sexual risk factors to be important in the possible causation of BV. We were able to confirm the link between cigarette smoking, multiple male sexual partners in past 12 months, $\geqslant 1$ female sexual partner in past 12 months, and infrequent condom use with BV in women attending sexual health clinic in Australia, along with the protective effect of hormonal contraception. In addition, we report association of BV with past pregnancies. More studies may be needed to confirm and evaluate the cause of this association. Our findings may be important for planning a preventive strategy for BV by discouraging smoking and increasing condom use and hormonal contraception among women.

\section{Authors' affiliations}

S Smart, A Singal, A Mindel, Sexually Transmitted Infections Research Centre, The University of Sydney, Marian Villa, Westmead Hospital, Westmead, NSW 2145, Australia

\section{REFERENCES}

1 Hillier S, Holmes KK. Bacterial vaginosis. In: Holmes KK, Sparling PF, Mårdh P-A, Lemon SM, Stamm WE, Piot P, Wasserheit JN, eds. Sexually transmitted diseases. 3rd ed. New York: McGraw-Hill, 1999.

2 Eschenbach DA, Hillier S, Critchlow C, et al. Diagnosis and clinical manifestations of bacterial vaginosis. Am J Obstet Gynecol 1988; 158:819-28

3 Goldenberg R, Klebanoff MA, Nugent R, et al. Bacterial colonization of the vagina during pregnancy in four ethnic groups. Am J Obstet Gynecol 1996;174:1618-21.

4 Cristiano L, Rampello S, Noris C, et al. Bacterial vaginosis: prevalence in an Italian population of asymptomatic pregnant women and diagnostic aspects. Eur J Epidemiol 1996;12:383-90.

5 Hay PE, Morgan DJ, Ison CA, et al. A longitudinal study of bacterial vaginosis during pregnancy. Br J Obstet Gynaecol 1994;101:1048-53.

6 Kurki T, Sivonen A, Renkonen OV, et al. Bacterial vaginosis in early pregnancy and pregnancy outcome. Obstet Gynecol 1992;80:173-7.

7 Riduan JM, Hillier SL, Utomo B, et al. Bacterial vaginosis and prematurity in Indonesia: association in early and late pregnancy. Am J Obstet Gynecol 1993; 169:175-8.

8 Puapermpoonsiri S, Kato N, Watanabe K, et al. Vaginal microflora associated with bacterial vaginosis in Japanese and Thai pregnant women. Clin Infect Dis 1996;23:748-752.

9 Hallen A, Pahlson C, Forsum U. Bacterial vaginosis in women attending STD clinic: diagnostic criteria and prevalence of Mobiluncus spp. Genitourin Med 1987;63:386-9.

10 Hill LH, Ruparelia H, Embil JA. Nonspecific vaginitis and other genital infections in three clinic populations. Sex Transm Dis 1983;10:114-18.

11 Harms G, Matull R, Randrianasolo D, et al. Pattern of sexually transmitted diseases in a Malagasy population. Sex Transm Dis 1994;21:315-20.

12 Hay PE. Therapy of bacterial vaginosis. J Antimicrob Chemother 1998;41:6-9. 
13 Kane KY, Pierce R. What are the most effective treatments for bacterial vaginosis in nonpregnant women? J Fam Pract 2001;50:399-400.

14 Hellberg D, Nilsson S, Mårdh PA. Bacterial vaginosis and smoking. Int J STD AIDS 2000;11:603-6.

15 Shoubnikova M, Hellberg D, Nilsson S, et al. Contraceptive use in women with bacterial vaginosis. Contraception 1997;55:355-8.

16 Nilsson U, Hellberg D, Shoubnikova M, et al. Sexual behavior risk factors associated with bacterial vaginosis and Chlamydia trachomatis infection. Sex Transm Dis 1997:24:241-6.

17 Calzolari E, Masciangelo R, Milite V, et al. Bacterial vaginosis and contraceptive methods. Int J Gynaecol Obstetet 2000;70:341-6.

18 Hart G. Factors associated with trichomoniasis, candidiasis and bacterial vaginosis. Int J STD AIDS 1993:4:21-5.

19 Goldenberg RL, Das A. Fetal fibronectin and bacterial vaginosis in smokers and nonsmokers. The National Institute of Child Health and Human Development Maternal-Fetal Medicine Units Network. Am J Obstet Gynecol 2000; 182(Pt 1):164-6.

20 Mardh PA. Bacterial vaginosis: a threat to reproductive health? Historical perspectives, current knowledge, controversies and research demands. Eur J Contracept Reprod Health Care 2000;5:208-19.

21 Wilson JD, Ralph SG, Rutherford AJ. Rates of bacterial vaginosis in women undergoing in vitro fertilisation for different types of infertility. $\mathrm{Br} J \mathrm{Obstet}$ Gynaecol 2002;109:714-17.

22 Pavlova SI, Tao L. Induction of vaginal Lactobacillus phages by the cigarette smoke chemical benzo(a)pyrene diol epoxide. Mutation Res 2000;466:57-62
23 Schwebke JR, Richey CM, Weiss HL Correlation of behaviors with microbiological changes in vaginal flora. J Infect Dis 1999;180:1632-6.

24 Fethers K, Marks C, Mindel A, et al. Sexually transmitted infections and risk behaviours in women who have sex with women. Sex Transm Infect 2000;76:345-9.

25 McCaffrey M, Varney P, Evans B, et al. Bacterial vaginosis in lesbians: evidence for lack of sexual transmission. Int J STD AIDS 1999;10:305-8.

26 Berger BJ, Kolton S, Zenilman JM, et al. Bacterial vaginosis in lesbians: a sexually transmitted disease. Clin Infect Dis 1995;21:1402-5.

27 Skinner CJ, Stokes J, Kirlew $Y$, et al. A case-controlled study of the sexual health needs of lesbians. Genitourin Med 1996;72:277-80.

28 Morris MC, Rogers PA, Kinghorn GR. Is bacterial vaginosis a sexually transmitted infection? Sex Transm Infect 2001;77:63-8.

29 Oakeshott P, Hay P, Hay S, et al. Association between bacterial vaginosis or chlamydial infection and miscarriage before 16 weeks gestation: prospective community based cohort study. BMJ 2003;325:1334.

$30 \mathrm{Moi}$. Prevalence of bacterial vaginosis and its association with genital infections, inflammation, and contraceptive methods in women attending sexually transmitted disease and primary health clinics. Int J STD AIDS 1990; 1:86-94.

31 Baeten JM, Nyange PM, Richardson BA, et al. Hormonal contraception and risk of sexually transmitted disease acquisition: results from a prospective study. Am J Obstet Gynecol 2001;185:380-5.

32 Hodoglugil NN, Aslan D, Bertan M. Intrauterine device use and some issues related to sexually transmitted disease screening and occurrence. Contraception 2000;61:359-64. 